\title{
COVID-19 Pandemic Impact on Physicians' Decision- making: Digoxin Toxicity in View of Combination of Hydroxychloroquine and Azithromycin: A Case Report
}

\author{
Mohammed Hamzah Mezaal ${ }^{1,2}$, Hasan Ali Farhan ${ }^{3,4}$, Zainab Atiyah Dakhil $^{5 *}$ (D) \\ ${ }^{1}$ IJn Al-Bitar Cardiac Centre, Baghdad, Iraq; ${ }^{2}$ Al-Yarmouk Teaching Hospital, Baghdad, Iraq; ${ }^{3}$ Scientific Council of Cardiology, \\ Iraqi Board for Medical Specializations, Baghdad, Iraq; ${ }^{4}$ Baghdad Heart Centre, Baghdad, Iraq; ${ }^{5}$ Department of Medicine, \\ Al-Kindy College of Medicine, University of Baghdad, Baghdad, Iraq
}

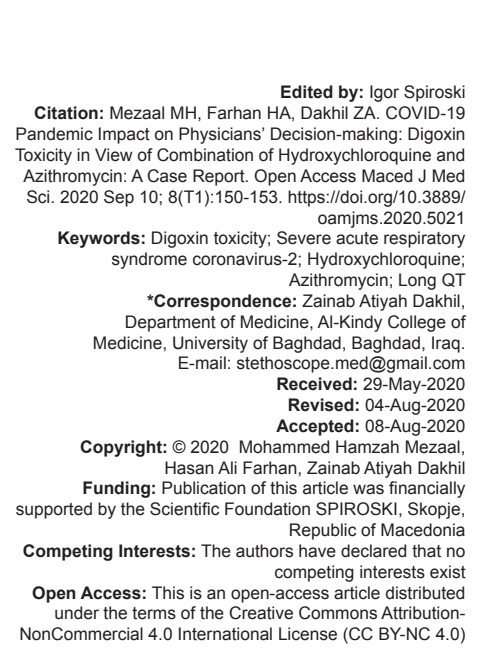

\begin{abstract}
BACKGROUND: Since the WHO declaration of COVID-19 being a global pandemic, the population in general and health-care providers, in particular, became under extraordinary pressure that remarkably impacts their decisions at multiple levels as all of us should make decisions quickly while being uncertain in many times.

CASE REPORT: We are reporting a 64 -year-old lady with a medical history of atrial fibrillation and mitral regurgitation that treated with digoxin and warfarin therapy, she was suspected to be a COVID-19 case and prescribed empirical hydroxychloroquine and azithromycin combination without proper adjustment of her baseline therapy, accordingly she developed adverse effect of this combination in the form of digoxin toxicity and long QT, this case highlights how this unprecedented pandemic affects the decision-making of physicians.

CONCLUSION: We should be critical and vigilant in making a decision of prescription or marketing non-evidencebased therapy, and when we are obligated for this decision, we should take all precautions to minimize the adverse
\end{abstract} effects of these drugs.

\section{Background}

Since the WHO declaration of COVID-19 being global pandemic on March 11, 2020 [1], the population in general and health-care providers, in particular, became under extraordinary pressure and in state of panic that remarkably impacts their decisions at multiple levels as all of us should make decisions quickly while being uncertain in many times. Amidst this unprecedented crisis, initial researchers found treating COVID-19 pneumonia with hydroxychloroquine ( $\mathrm{HCQ}$ ) might increase the rate of treatment success, shorten hospitalization, as well as improve outcomes [2]. Others suggested that there was a synergistic effect of the combination of $\mathrm{HCQ}$ and azithromycin (AZ) in decreasing viral load and recommended its use to cure COVID-19 patients with subsequent transmission control; however, the study pointed to possible prolongation of QT interval with use of this combination [3]. On March 28, 2020, FDA issued an emergency use authorization that allowed for the use of the drugs to treat patients with COVID-19 [4].
Accordingly, physicians started using this combination therapy worldwide in the hope to decrease this pandemic burden. We are reporting a patient with multiple comorbidities who was suspected to be a COVID-19 case and prescribed empirical $\mathrm{HCQ}$ and $\mathrm{AZ}$ combination then developed adverse effect of this therapy, this case highlights how COVID-19 pandemic affects the decisionmaking of physicians.

\section{Case Presentation}

A 64-year-old lady had history of hypertension, and moderate mitral regurgitation (MR) due to mitral valve prolapse and paroxysmal atrial fibrillation, for which she was prescribed 1 month before presentation a digoxin tablet $0.25 \mathrm{mg}$ and a warfarin tablet $5 \mathrm{mg}$; both once daily.

During peak of country lockdown and COVID-19 pandemic panic in Iraq at March 26, 2020, the patient was presented to the ER of a teaching hospital complaining 
of nausea and vomiting, she denied fever and respiratory symptoms; however, in the era of COVID-19 pandemic the treating physician requested chest CT scan which showed bilateral ground-glass opacity Figure 1, so COVID-19 was his provisional diagnosis. She sought the second opinion by consulting other physician who prescribed HCQ (200 mg twice daily) and AZ (500 mg once daily) without adjusting the baseline therapy, and he recommended her being self-quarantined at home.

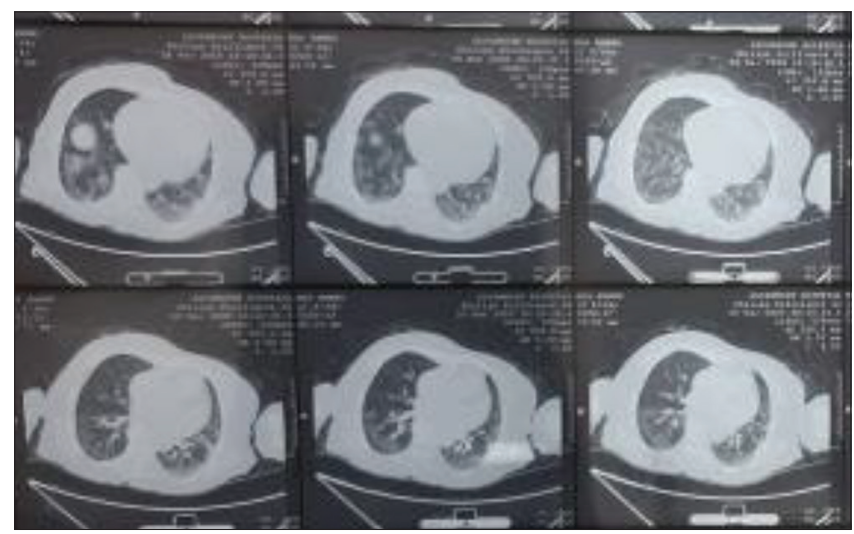

Figure 1: Initial chest computed tomography scan showing bilateral ground-glass infiltrates (in the first hospital)

Two days later, the patient was presented to our facility complaining from abdominal pain, nausea, and vomiting, her examination was remarkable only for heart rate HR of $35 \mathrm{bpm}$; on further inquiry, she denied syncope or presyncope.

New electrocardiography (ECG) revealed complete heart block (CHB) with escape junctional rhythm, diffuse ST-depression with reverse tick appearance, with long QT interval, these changes were new compared to a previous ECG done 10 days before presentation (on an outpatient clinic follow-up visit for her valve problem), Figure 2a-d. Her biochemical profile revealed elevated renal indices: Blood urea was $115 \mathrm{mg} / \mathrm{dL}$, serum creatinine was $2.3 \mathrm{mg} / \mathrm{dL}$, electrolyte and liver function tests were normal, and her INR was 1.6. The second chest CT scan was done again as she did not inform her treating team about the first chest CT that was done earlier, the second CT scan confirmed the same findings, so the patient was presumed to be a COVID-19 case based on her chest CT findings.

The main provisional diagnosis was digoxin toxicity induced by her impaired renal function and interaction of digoxin with additive potentiation of $\mathrm{HCQ}, A Z$, and warfarin resulting in long QT and CHB. Accordingly, the patient was admitted to a quarantined CCU where she was the only patient there, nasal and throat swabs were taken and sent for polymerase chain reaction (PCR) for severe acute respiratory syndrome coronavirus-2 (SARS-CoV2), she was kept under monitoring, while hydroxychloroquine, azithromycin and digoxin were all withheld. She was treated conservatively with frequent atropine injections; $0.6 \mathrm{mg}$ as needed. At first in-hospital day, the patient heart rate was $30 \mathrm{bpm}$, so resident on-call gave her frequent atropine injections

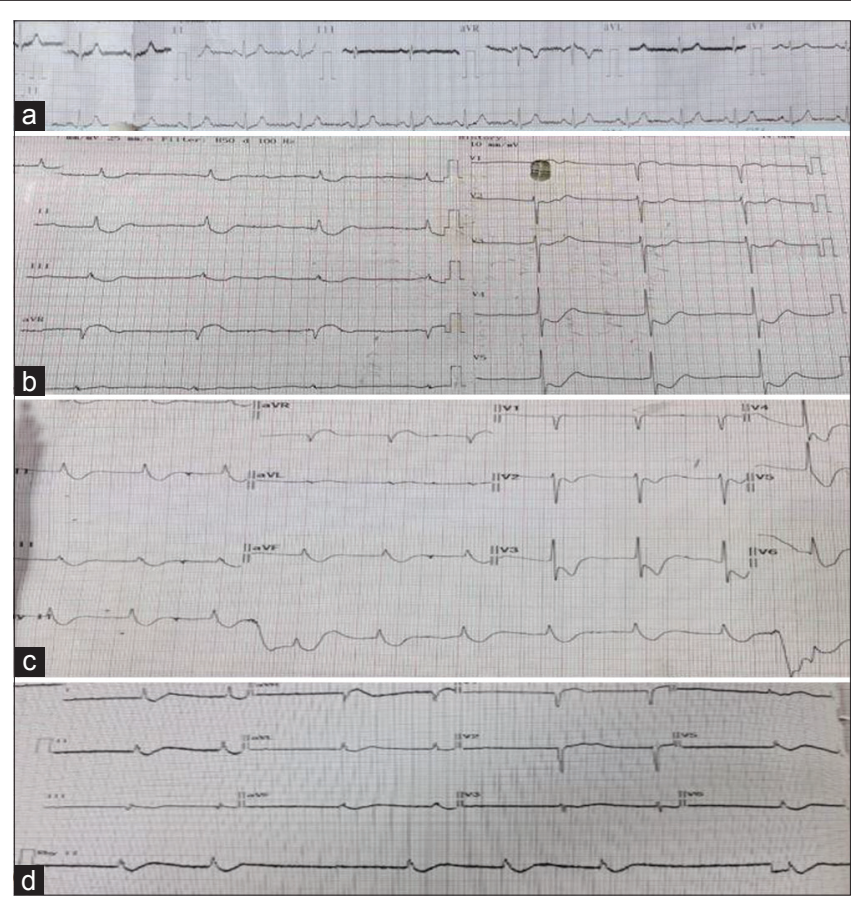

Figure 2: Serial electrocardiography (ECG) of the patient (a) Baseline ECG (before presentation) with normal sinus rhythm. (b) Complete heart block with the regular ventricular response, generalized down sagging ST depression with QTC interval of $411 \mathrm{msec}$ (at presentation). (c) Second in-hospital day ECG with a heart rate of $75 \mathrm{bpm}$ after atropine therapy and QTc of $408 \mathrm{msec}$. (d) Third in-hospital day ECG showing complete heart block with a junctional escape rhythm

(up to $3 \mathrm{mg}$ ), few hours later, the patient developed confusion (at this point heart rate was $60 \mathrm{bpm}$ ), brain CT was unremarkable, the treating physician considered this confusion as an adverse effect of atropine. Hence, the patient was kept under observation, and she regained full consciousness $8 \mathrm{~h}$ later.

Twenty-four hours later, the result of PCR was negative for SARS-CoV2. An echocardiography was done to assess her valve problem, and it showed moderate eccentric MR with prolapsing anterior mitral valve leaflet, good left ventricular function.

The patient was responding to conservative measures with HR returning to $60 \mathrm{bpm}$ with a junctional rhythm. She was discharged after 5 days on April 2, 2020. Then, she was followed up on an outpatient basis for the next 10 days, she denied any symptoms and returned to sinus rhythm with a rate of (67) bpm, Figure 3.

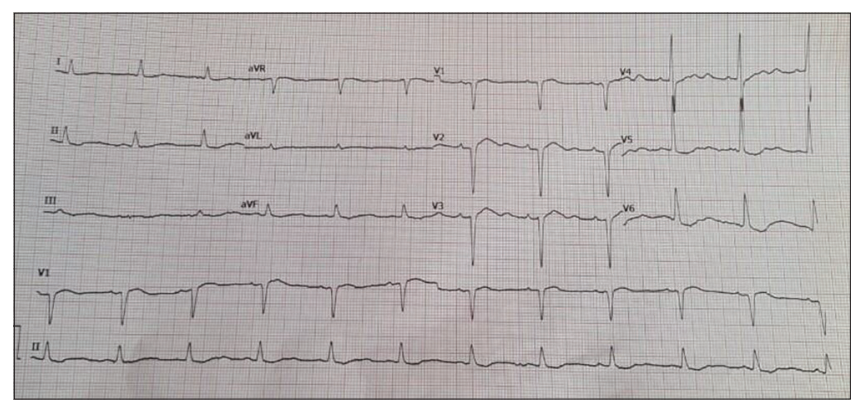

Figure 3: Electrocardiography on follow up visit 10 days after discharge, showing a heart rate of $67 \mathrm{bpm}$ and nonspecific ST-T changes 


\section{Discussion}

Digoxin is a cardiac glycoside derived from the purple foxglove flower, it is a commonly prescribed drug in practice for heart failure and/or atrial fibrillation [5]. It has very narrow therapeutic index with very wide spectrum of drugs interactions, which made digoxin toxicity once very common; however, it is declining in modern era due to use of alternative drugs in heart failure with greater impact on prognosis and use of more accurate dosing methods [6], among potential causes for digoxin toxicity are coprescription of drugs that increase digoxin absorption or decrease digoxin renal excretion without proper adjustment of digoxin dosage [7]. Macrolide antibiotics are such examples as known to increase digoxin levels by inhibition of P-glycoprotein by reducing energy-dependent digoxin transport from enterocytes into intestinal lumen and limiting transport into the lumen of the nephron [8], [9]. Despite AZ less 4 times than clarithromycin to cause digoxin toxicity, it still can remarkably cause digoxin toxicity [10] as occurred in this patient. $\mathrm{HCQ}$ also reported to increase digoxin level mostly due to digoxin displacement from its binding site in tissues or by decreasing renal clearance [11], [12]. Furthermore, this patient was on warfarin therapy which was reported to cause significant interaction with digoxin [13], [14], such polypharmacy was the main driving cause for digoxin toxicity here especially in view of renal impairment. Digoxin toxicity can manifest as gastrointestinal complaints such as nausea, vomiting, and abdominal pain as occurred in this patient or visual disturbance such as yellow vision and neurological manifestations such as headache, lethargy confusion, dizziness, and delirium [15], [16]. Despite this patient had confusion that could be explained by digoxin toxicity or $\mathrm{CHB}$, we think that atropine use can explain this neurological manifestation as atropine was reported to cause such adverse effect especially that the onset of confusion was after atropine administration and her accepted heart rate at time of confusion contradicted $\mathrm{CHB}$ as an explanation for this manifestation [17], [18]. Digoxin toxicity can cause many ECG changes, including frequent PVC, junctional tachycardia, junctional rhythm, heart block, atrial fibrillation, atrial flutter, premature atrial contractions, sinus arrest, sinus bradycardia or tachycardia, wandering pacemaker, ventricular tachycardia, or ventricular fibrillation [19]. It is noteworthy to mention that scooping ST-T changes and reverse tick sign in ECG of this patient are considered digitalis effect, that is, they can occur with digoxin in a therapeutic range not necessarily in the toxic range [16]. This patient had CHB with a junctional escape rhythm signifying cardiotoxicity from digoxin. She did not only have digoxin toxicity due to multiple drugs interaction and renal impairment but also prolonged QT interval due to combination of $H C Q$ and $A Z$ which were reported to cause prolonged QT due to blocking of human ether-a-go-go-related gene potassium canal resulting in slow cardiac repolarization [20]. Drug- induced long QT is more to occur in elderly, females, patients with hypoxia, cardiovascular diseases, and metabolic derangement [21], [22]. This patient is a female with structural heart disease and on digoxin and warfarin which can interact remarkably with HCQ-AZ combination, all that resulted in higher risk for developing long QT. Measurement of serum digoxin level and FAB treatment is not available in our facility making the main treatment of digoxin toxicity in this patient by withholding the offending drugs with supportive measures like atropine. Another interesting point, in this case, was the groundglass opacity finding in chest CT scan, as COVID-19 mainly was excluded by negative PCR, with no clinical evidence of other pulmonary infections in term of fever nor cough, despite acute MR was reported to cause ground-glass opacity [23], no literature reported such finding in chronic MR; however, we think that subclinical pulmonary congestion can be a possibility for such finding as volume overload was reported to cause such radiological manifestation [24].

This patient was not confirmed to be a COVID-19 case nor being critical enough to justify prescribing non-evidence-based drugs such as $A Z$ and $H C Q$, especially in view of other drugs with potential interactions like digoxin or warfarin without proper dosage adjustment.

During this emergency pandemic, it is well understood that FDA should act quickly and effectively, trying to facilitate all steps toward fulfilling the eager population expectation to find the proper treatment for COVID-19, including experimental therapy based on no proper randomized trials. However, we, as physicians, academics, and researchers, should be critical and vigilant in making a decision of prescription or marketing non-evidence-based therapy and when we are obligated for this decision, we should take all precautions to minimize adverse effects of these drugs.

\section{References}

1. World Health Organization. WHO Announces COVID-19 Outbreak a Pandemic; 2020. Available from: http://www.euro. who.int/en/health-topics/health-emergencies/coronaviruscovid-19/news/news/2020/3/who-announces-covid-19outbreak-a-pandemic. [Last accessed on 2020 May 07].

2. Jie Z, He H, Xi H, Zhi Z. Expert consensus on chloroquine phosphate for the treatment of novel coronavirus pneumonia. Zhonghua Jie He He Hu Xi Za Zhi. 2020;43:E019.

PMid:32075365

3. Gautret P, Lagier JC, Parola P, Meddeb L, Mailhe M, Doudier B, et al. Hydroxychloroquine and azithromycin as a treatment of COVID-19: Results of an open-label non-randomized clinical trial. Int J Antimicrob Agents. 2020;56(1):105949. https://doi. org/10.1016/j.ijantimicag.2020.105949

PMid:32205204

4. Rome BN, Avorn J. Drug evaluation during the COVID-19 
pandemic. N Engl J Med. 2020;382(24):2282-4. https://doi. org/10.1056/nejmp2009457

\section{PMid:32289216}

5. Nguyen T. Digoxin Use in Modern Medicine. U S Pharm. 2015;40(2):44-8. Available from: https://www.uspharmacist. com/article/digoxin-use-in-modern-medicine. [Last accessed on 2020 May 15].

6. Bauman JL, DiDomenico RJ, Galanter WL. Mechanisms, manifestations, and management of digoxin toxicity in the modern era. Am J Cardiovasc Drugs. 2006;6(2):77-86. https:// doi.org/10.2165/00129784-200606020-00002

PMid: 16555861

7. Adis Medical Writers. Understanding the mechanisms and manifestations of digoxin toxicity helps in its management and treatment. Drugs Ther Perspect. 2007;23:20-3.

8. Wakasugi H, Yano I, Ito T, Hashida T, Futami T, Nohara R, et al. Effect of clarithromycin on renal excretion of digoxin: Interaction with P-glycoprotein. Clin Pharmacol Ther. 1998;64(1):123-8. https://doi.org/10.1016/s0009-9236(98)90030-3 PMid:9695727

9. Eberl S, Renner B, Neubert A, Reisig M, Bachmakov I, König J, et al. Role of P-glycoprotein inhibition for drug interactions: Evidence from in vitro and pharmacoepidemiological studies. Clin Pharmacokinet. 2007;46(12):1039-49. https://doi. org/10.2165/00003088-200746120-00004 PMid:18027988

10. Gomes T, Mamdani MM, Juurlink DN. Macrolide-induced digoxin toxicity: A population-based study. Clin Pharmacol Ther. 2009;86(4):383-6. https://doi.org/10.1038/clpt.2009.127 PMid:19606089

11. Hromadkova L, Soukup T, VIcek J. Important drug interactions in patients with rheumatic disorders: Interactions of glucocorticoids, immunosuppressants and antimalarial drugs. Drugs Today (Barc). 2012;48(8):545.

PMid:22916342

12. Leden I. Digoxin-hydroxychloroquine interaction? Acta Med Scand. 1982;211(5):411-2.

PMid:7113754

13. Bhattacharyya A, Bhavnani M, Tymms DJ. Serious interaction between digoxin and warfarin. $\mathrm{Br} \mathrm{J}$ Cardiol. 2002;9(6):356-7. Available from:https://www.bjcardio.co.uk/2002/06/seriousinteraction-between-digoxin-and-warfarin. [Last accessed on 2020 May 15].

14. Gooderham MJ, Bolli P, Fernandez PG. Concomitant digoxin toxicity and warfarin interaction in a patient receiving clarithromycin. Ann Pharmacother. 1999;33(7-8):796-9. https:// doi.org/10.1345/aph.18330

15. Menon AS, Abdullah $M$, Jinesh $V$, Moideen F. Digoxin dilemma. BMH Med J. 2016;3(4):100-3. Available from: https:// www.babymhospital.org/bmh_mj/index.php/bmhmj/article/ view/101/259. [Last accessed on 2020 May 15].

16. Wetherell H. Digoxin and the heart. Br J Cardiol. 2015;22:967. Available from: https://www.bjcardio.co.uk/2015/08/digoxinand-the-heart. [Last accessed on 2020 May 15].

17. Dogukan M. Atropine-Induced Delirium which Developed during Treatment of Organophosphate Intoxication in Adult: A Case Report, Research; 2014. https://doi.org/10.13070/rs.en.1.1073

18. Erol DD, Geçici Ö. Central anticholinergic syndrome secondary to atropine treatment of organophosphate poisoning. Psychogeriatrics. 2006;6(3):145-6. https://doi. org/10.1111/j.1479-8301.2006.00149.x

19. Ma G, Brady WJ, Pollack M, Chan TC. Electrocardiographic manifestations: Digitalis toxicity. J Emerg Med. 2001;20(2):145-52.

PMid:11207409

20. Giudicessi J, Ackerman M. Azithromycin and risk of sudden cardiac death: Guilty as charged or falsely accused? Cleve Clin J Med. 2013;80(9):539-44. https://doi.org/10.3949/ ccjm.80a.13077 PMid:24001961

21. Hancox JC, Hasnain M, Vieweg WV, Crouse EL, Baranchuk A. Azithromycin, cardiovascular risks, QTc interval prolongation, torsade de pointes, and regulatory issues: A narrative review based on the study of case reports. Ther Adv Infect Dis. 2013;1(5):155-65. https://doi.org/10.1177/2049936113501816 PMid:25165550

22. Mitra RL, Greenstein SA, Epstein LM. An algorithm for managing QT prolongation in coronavirus disease 2019 (COVID-19) patients treated with either chloroquine or hydroxychloroquine in conjunction with azithromycin: Possible benefits of intravenous lidocaine. Heart Rhythm Case Rep. 2020;6(5):244-8. https://doi. org/10.1016/j.hrcr.2020.03.016

PMid:32363145

23. Woolley K, Stark P. Pulmonary parenchymal manifestations of mitral valve disease. Radiographics. 1999;19(4):965-72. https:// doi.org/10.1148/radiographics.19.4.g99jl10965 PMid: 10464803

24. Hewitt MG, Miller WT Jr., Reilly TJ, Simpson S. The relative frequencies of causes of widespread ground-glass opacity: A retrospective cohort. Eur J Radiol. 2014;83(10):1970-6. https:// doi.org/10.1016/j.ejrad.2014.06.025

PMid:25082478 